\title{
Physiologically based indices of volumetric capnography in patients receiving mechanical ventilation
}

\author{
P.V. Romero*, U. Lucangelo**, J. Lopez Aguilar*, R. Fernandez**, L. Blanch**
}

Physiologically based indices of volumetric capnography in patients receiving mechanical ventilation. P.V. Romero, U. Lucangelo, J. Lopez Aguilar, R. Fernandez, L. Blanch. CERS Journals Ltd 1997.

ABSTRACT: Several indices of ventilatory heterogeneity can be identified from the expiratory $\mathrm{CO}_{2}$ partial pressure or $\mathrm{CO}_{2}$ elimination versus volume curves. The aims of this study were: 1) to analyse several computerizable indices of volumetric capnography in order to detect ventilatory disturbances; and 2) to establish the relationship between those indices and respiratory system mechanics in subjects with normal lungs and in patients with acute respiratory distress syndrome (ARDS), both receiving mechanical ventilation.

We studied six normal subjects and five patients with early ARDS mechanically ventilated at three levels of tidal volume $(V T)$. Respiratory system mechanics were assessed by end-expiratory and end-inspiratory occlusion methods, respectively. We determined Phase III slopes, Fletcher's efficiency index, Bohr's dead space $\left(V \mathrm{D}, \mathrm{Bohr} / V_{\mathrm{T}}\right)$, and the ratio of alveolar ejection volume to tidal volume $(V \mathrm{AE} / V \mathrm{~T})$ from expiratory capnograms, as a function of expired volume.

Differences between normal subjects and ARDS patients were significant both for capnographic and mechanical parameters. Changes in VT significantly altered capnographic indices in normal subjects, but failed to change ventilatory mechanics and $V \mathrm{AE} / V_{\mathrm{T}}$ in ARDS patients. After adjusting for breathing pattern, $V \mathrm{AE} / V \mathrm{~T}$ exhibited the best correlation with the mechanical parameters.

In conclusion, volumetric capnography, and, specifically, the ratio of alveolar ejection volume to tidal volume allows evaluation and monitoring of ventilatory disturbances in patients with adult respiratory distress syndrome.

Eur Respir J 1997; 10: 1309-1315.
*Servei de Pneumologia i Unitat de Recerca Experimental, Hospital Universitari de Bellvitge, L'Hospitalet de Llobregat, **Servei de Medicina Intensiva, Hospital de Sabadell, Sabadell, Spain.

Correspondence: P.V. Romero Laboratori de Funció Pulmonar Servei de Pneumologia

Hospital Universitari de Bellvitge c. Feixa Llarga $\mathrm{s} / \mathrm{n}$ 08907-L'Hospitalet de Llobregat Spain

Keywords: Acute respiratory distress syndrome

mechanical ventilation tidal volume

volumetric capnography

Received: April 101996

Accepted after revision February 211997

This work was partially supported by Grant 94/1542 from the Fondo de Investigaciones Sanitarias del Ministerio de Sanidad y Consumo, Spain. J.L.A. was a fellow from Fundació August Pi i Sunyer.
Carbon dioxide partial pressure of expired air $\left(P \mathrm{E}, \mathrm{CO}_{2}\right)$ increases progressively in a typical three phase curve: Phase I corresponds to the expiration of gas from the apparatus and anatomical dead space; Phase II shows a rapid rise in $P \mathrm{E}, \mathrm{CO}_{2}$ due to exhalation of mixed air; and Phase III shows a plateau with a small positive slope in normal subjects. Changes in the morphology of the capnographic curve often indicate ventilatory maldistribution. In order to quantify these disturbances, several indices based on the geometric analysis of the curve have been developed [1-3], and among them the alveolar plateau slope is the most frequently used [4-7].

When expiratory partial $\mathrm{CO}_{2}$ pressure is plotted as a function of time $\left(P \mathrm{E}, \mathrm{CO}_{2}(t)\right.$ curve), expiratory flow has to be taken into account even in healthy subjects [4, 8]. This constraint has led to the use of volumetric capnography, i.e. the expiratory partial pressure of $\mathrm{CO}_{2}$ as a function of the volume or $P \mathrm{E}, \mathrm{CO}_{2}(V)$ curve $[4,5$, 9]. Nonetheless, alveolar slope indices are still dependent on the visual criterion used to define Phase III [1]. To overcome this limitation, computerizable physiologically based indices need to be developed, and their validity should be compared. Unlike geometric measurements, physiologically based indices give direct information about functional disturbances of ventilatory distribution.
A different approach to volumetric capnography is represented by the use of the $\mathrm{CO}_{2}$ elimination versus volume curve $\left(V^{\prime} \mathrm{CO}_{2}(V)\right.$ curve). This curve has been used successfully in the measurement of anatomical dead space by linear back extrapolation of the increase of $V^{\prime} \mathrm{CO}_{2}$ with volume $[5,10]$. A physiological assumption would allow the identification of the fraction of tidal volume corresponding to the exhalation of alveolar gas ( $V \mathrm{AE})$. This process can be easily computerized, and would represent a substantial improvement in the automation of the quantitative analysis of the overall curve.

Therefore, the aims of this study were: 1) to analyse several computerizable indices of volumetric capnography in order to detect ventilatory disturbances; and 2) to establish the relationship between those indices and respiratory system mechanics in subjects with normal lungs, and in patients with acute respiratory distress syndrome (ARDS), both receiving mechanical ventilation.

\section{Materials and methods}

\section{Subjects}

The study was performed on 11 patients, distributed into two groups: Normal group comprising six subjects, 
aged $24 \pm 11$ yrs (mean $\pm \mathrm{SD}$ ), having a normal chest radiograph and without history of cardiopulmonary disease, who were studied immediately before minor scheduled nonthoracic surgery; ARDS group comprising five patients, aged $55 \pm 17$ yrs, with early severe ARDS, Lung Injury Score [11] of $2.99 \pm 0.31$ (mean \pm SD), and without previous history of chronic obstructive pulmonary disease (COPD) or asthma, who were studied during the first $72 \mathrm{~h}$ of mechanical ventilation at the intensive care unit (ICU). The study protocol was approved by the Ethics Committee for Clinical Investigation in the Hospital of Sabadell, Spain.

Subjects were transorally intubated with a cuffed endotracheal tube (Hi-lo Evac Mallinckrodt Lab., Athlone, Ireland), internal diameter (ID) 7.5-8.5 mm. Anaesthesia and paralysis were maintained with propofol (4-12 $\left.\mathrm{mg} \cdot \mathrm{kg}^{-1} \cdot \mathrm{h}^{-1}\right)$, phentanyl $\left(3 \mu \mathrm{g} \cdot \mathrm{kg}^{-1}\right)$ and atracurium besylate $\left(0.3-0.6 \mathrm{mg} \cdot \mathrm{kg}^{-1} \cdot \mathrm{h}^{-1}\right)$. Subjects were mechanically ventilated in control mode with constant inspiratory flow (Servo 900C; Siemens, Solna, Sweden) at zero end-expiratory pressure (ZEEP). Basal respiratory frequency $(f R)$ and tidal volume $(V \mathrm{~T})$ were adjusted to maintain endtidal carbon dioxide tension $\left(P \mathrm{ET}, \mathrm{CO}_{2}\right)$ values between $4.3-4.8 \mathrm{kPa}(32-36 \mathrm{mmHg})$ in normal subjects. Basal $V \mathrm{~T}$ in ARDS patients ranged $6-10 \mathrm{~mL} \cdot \mathrm{kg}^{-1}$ and hypercapnia was allowed during mechanical ventilation. Maintenance ventilatory parameters in normal subjects and in ARDS patients are depicted in table 1 .

\section{Physiological measurements}

Tracheal pressure $(P \operatorname{tr})$ was measured using a noncompliant polyethylene catheter $(50 \mathrm{~cm}$ long, $1.5 \mathrm{~mm}$ ID) with multiple distal holes, connected to a pressure transducer (MicroSwitch 163PC05D36; Honeywell Ltd, Scarborough, Ontario, Canada). The tracheal catheter was placed $1.5-2.0 \mathrm{~cm}$ past the distal end of the endotracheal tube (ETT). The frequency response of the catheter was tested and results were linear up to $20 \mathrm{~Hz}$. Airflow $\left(V^{\prime}\right)$ was measured by a heated Fleisch No. 2 pneumotachograph (Metabo, Epalinges, Switzerland) placed via cones between the ETT and the Y-connector of the ventilator. A linear piezoelectric differential pressure transducer (MicroSwitch 163PC01D36; Honeywell Ltd) was connected to the pneumotachograph. The response of the pneumotachograph was linear over the experimental range of flows. $V \mathrm{~T}$ was obtained by digital integration of the flow signal. To reduce the effects of the compliance of the ventilator tubing on the mechanical measurements, low-compliance tubing $\left(0.4 \mathrm{~mL} \cdot \mathrm{hPa}^{-1}\right)$ was

Table 1. - Maintenance ventilatory parameters in normal subjects and in patients with ARDS

\begin{tabular}{lll}
\hline & \multicolumn{1}{c}{$\begin{array}{c}\text { Normal } \\
\text { group }\end{array}$} & $\begin{array}{c}\text { ARDS } \\
\text { group }\end{array}$ \\
\hline$V \mathrm{~T} \quad \mathrm{~L}$ & $0.56 \pm 0.03$ & $0.49 \pm 0.06$ \\
$f \mathrm{R} \mathrm{min}^{-1}$ & $12.7 \pm 0.6$ & $22.8 \pm 4.1$ \\
$V^{\prime} \mathrm{L} \cdot \mathrm{s}^{-1}$ & $0.72 \pm 0.02$ & $0.74 \pm 0.14$ \\
$t \mathrm{I} \mathrm{S}$ & $1.18 \pm 0.07$ & $0.75 \pm 0.16$ \\
$t$ tot $\mathrm{S}$ & $4.74 \pm 0.25$ & $2.69 \pm 0.44$ \\
\hline
\end{tabular}

Values are presented as mean \pm SD. ARDS: acute respiratory distress syndrome; $V \mathrm{~T}$ : tidal volume; $f \mathrm{R}$ : respiratory frequency; $V^{\prime}$ : inspiratory airflow; $t \mathrm{I}$ : inspiratory time; $t$ tot: total respiratory cycle. used and the heat and moisture exchanger was omitted. Calibrations were performed before each study.

Respiratory system mechanics in relaxed patients were assessed by end-inspiratory and end-expiratory occlusions [12]. When a rapid end-inspiratory occlusion is performed, a drop in $P$ tr from a maximal value $(P \max )$ to $P 1$ occurs. During the $4 \mathrm{~s}$ end-inspiratory occlusion manoeuvre $P$ tr gradually decays from $P 1$ to an apparent plateau $\left(P_{2}\right)$, which represents the end-inspiratory static recoil pressure of the total respiratory system. Both $P \max$ and $P 1$ were corrected for errors introduced by the closing time of the ventilator valve, as described previously [13]. End-expiratory occlusion was maintained until tracheal pressure reached a plateau (usually $3 \mathrm{~s}$ ). This manoeuvre allowed the measurement of intrinsic PEEP (PEEPi). Respiratory system compliance $(C \mathrm{rs})$ was determined as $V$ T divided by elastic recoil pressure minus PEEPi. Respiratory system resistance (Rrs), and its subdivisions (the Newtonian component of $R$ rs $(R \min , \mathrm{rs})$ and differential resistance $(\Delta R \mathrm{rs}))$ were obtained by dividing $P \max -P_{2}, P_{\max }-P_{1}$ and $P 1-P 2$, respectively, by the inspiratory flow previous to inspiratory occlusion. Total resistance $(R$ tot $)$ was determined by adding the measured tube resistance to $R$ rs.

$P$ E, $\mathrm{CO}_{2}$ was recorded by means of a mainstream capnograph $\left(\mathrm{CO}_{2} /\right.$ fraction of inspired oxygen $\left(F \mathrm{I}, \mathrm{O}_{2}\right)$ Module HP78556A; Hewlett Packard, Palo Alto, CA, USA) placed between the pneumotachograph and the endotracheal tube. The total instrumental dead space added was $80 \mathrm{~mL}$. The expiratory parts of volume and $P \mathrm{E}, \mathrm{CO}_{2}$ signals were isolated using the flow signal as a reference. Instantaneous $\mathrm{CO}_{2}$ elimination $\left(V^{\prime} \mathrm{CO}_{2}\right)$ was obtained by digital integration of the $P \mathrm{E}, \mathrm{CO}_{2}$ signal at differential increments of volume.

Signals were amplified and filtered at a corner frequency of $100 \mathrm{~Hz}$ (ECLER 8-poles Bessel filter; Barcelona, Spain) sampled at $250 \mathrm{~Hz}$ by means of an analogue-todigital (A/D) converter (Data Translation; DT-2801A, Marlboro, MA, USA) and stored in magnetic media for off-line processing.

\section{Protocol}

This study involved applying three levels of tidal volume at ZEEP, fixed inspiratory:expiratory (I:E) ratio and constant minute ventilation ( $V^{\prime} \mathrm{E}$ ) by adjusting the respiratory rate of the ventilator. Using this approach, inspiratory time lengthened, while the relationship between inspiratory time and respiratory duty cycle remained constant. Each $V \mathrm{~T}$ variation was preceded by careful aspiration of pulmonary secretions and a sequence of three sighs to standardize lung volume history. Three regular breaths followed by end-inspiratory and endexpiratory occlusions were recorded in random order at high, low and mid tidal volume. A period of $5 \mathrm{~min}$ of basal breathing pattern elapsed between each determination.

\section{Calculation of capnographic indices on the $P \mathrm{E}, \mathrm{CO}_{2}(V)$ curve}

The following computerized capnographic indices were obtained from the $\mathrm{PE}, \mathrm{CO}_{2}$ versus volume curve: 
1) Slope of Phase III of $P \mathrm{E}, \mathrm{CO}_{2}$ as a function of the expiratory volume curve was determined to be between $50 \%$ of expired volume and the end-tidal point (S150), and between $75 \%$ of expired volume and the end-tidal point (S175), by least squares linear regression. Because hyperventilation to a low $P \mathrm{ET}, \mathrm{CO}_{2}$ decreases the slope of Phase III, the slope in $\mathrm{mmHg} \cdot \mathrm{L}^{-1}$ was normalized by dividing it by $P \mathrm{ET}, \mathrm{CO}_{2}$. These normalized slopes $(\mathrm{Sl} 50 \mathrm{~N}$, and $\mathrm{S} 175 \mathrm{~N}$ in $\mathrm{L}^{-1}$ ) relate more closely to the spread of ventilation/perfusion $\left(V^{\prime} / Q^{\prime}\right)$ ratios [9].

2) The classical Bohr estimation of alveolar dead space was calculated according to the equation $[14,15]$ :

$$
V \mathrm{D}, \mathrm{Bohr} / V \mathrm{~T}=\left(P \mathrm{ET}, \mathrm{CO}_{2}-\bar{P} \mathrm{E} \mathrm{CO}_{2}\right) / P \mathrm{ET}, \mathrm{CO}_{2}
$$

where $P$ ET, $\mathrm{CO}_{2}$ is end-tidal $P$ E, $\mathrm{CO}_{2}$, and $\bar{P}$ E, $\mathrm{CO}_{2}$ is the mean $P$ E, $\mathrm{CO}_{2}$, calculated from: $\bar{P} \mathrm{E}, \mathrm{CO}_{2}=V^{\prime} \mathrm{CO}_{2}$ tot $/ V \mathrm{~T} ; V^{\prime} \mathrm{CO}_{2}$ tot being the total amount of $\mathrm{CO}_{2}$ eliminated in a single expiration.

3) Fletcher's [9] efficiency index (Eff) was also calculated as the ratio:

$$
\text { Eff }=V^{\prime} \mathrm{CO}_{2}, \text { tot } /\left(F \mathrm{ET}, \mathrm{CO}_{2} \cdot V \mathrm{~T}, \text { eff }\right)
$$

where $V$ T,eff is the sum of Phases II and III, and $F$ ET, $\mathrm{CO}_{2}$ is the end-tidal $\mathrm{CO}_{2}$ fraction. When the $P \mathrm{E}, \mathrm{CO}_{2}$ versus volume curve approaches a rectangular shape, efficiency approaches one. To scale this index for the same order of values (0 to 1) used for $V \mathrm{D}, \mathrm{Bohr} / V \mathrm{~T}$ and $V \mathrm{AE} / V \mathrm{~T}$, it was corrected as Effc $=($ Eff-0.5) $\times 2$.

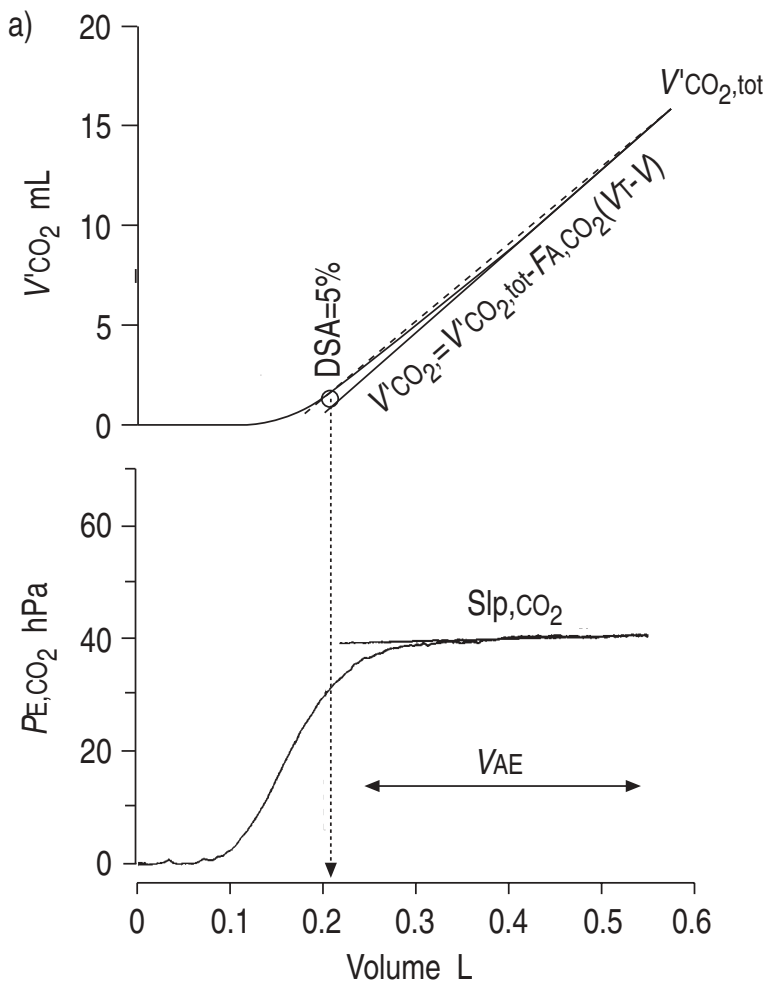

4) The method of VAE determination in a normal subject and in an ARDS patient is presented in figure 1. Figure 1 shows $P$ E, $\mathrm{CO}_{2}(V)$ and $V^{\prime} \mathrm{CO}_{2}(V)$ curves as a function of expired volume in a representative breath. After a given volume has been exhaled, $V^{\prime} \mathrm{CO}_{2}$ increases progressively to reach $V^{\prime} \mathrm{CO}_{2}$, tot . The increase in $V^{\prime} \mathrm{CO}_{2}$ is slightly nonlinear because of alveolar nonhomogeneity, i.e. the presence of a certain amount of alveolar gas contaminated by parallel dead space. At the very end of expiration, exhaled gas comes only from alveoli, representing pure alveolar gas. Assuming a fixed amount of dead space contamination (dead space allowance (DSA)), we can obtain a point on the $V^{\prime} \mathrm{CO}_{2}(V)$ curve representing the beginning of the alveolar gas ejection volume $(V \mathrm{AE})$. After evaluation of the variability and the noiseto-signal ratio (NSR) of the $V \mathrm{AE}$ determined at increasing percentages of DSA, we considered $0.05(5 \%)$ to be the lowest value of DSA that could be accepted, with a reasonable margin of variability $(<15 \%)$ and having a NSR lower than $50 \%$ both in normal subjects and in ARDS patients.

The $V$ AE was then measured from the $V^{\prime} \mathrm{CO}_{2}(V)$ curve as follows: firstly, the slope of the last 50 points of every cycle was obtained by linear fitting, using the least squares method. Then $V \mathrm{AE}$ was obtained as the value of the volume at the intersection between the $V^{\prime} \mathrm{CO}_{2}(V)$ curve and a straight line, having a maximal value at end-expiration and a slope equal to 0.95 (1-DSA) times the calculated slope (fig. 1a). VAE is expressed as fraction of tidal volume $(V \mathrm{AE} / V \mathrm{~T})$.

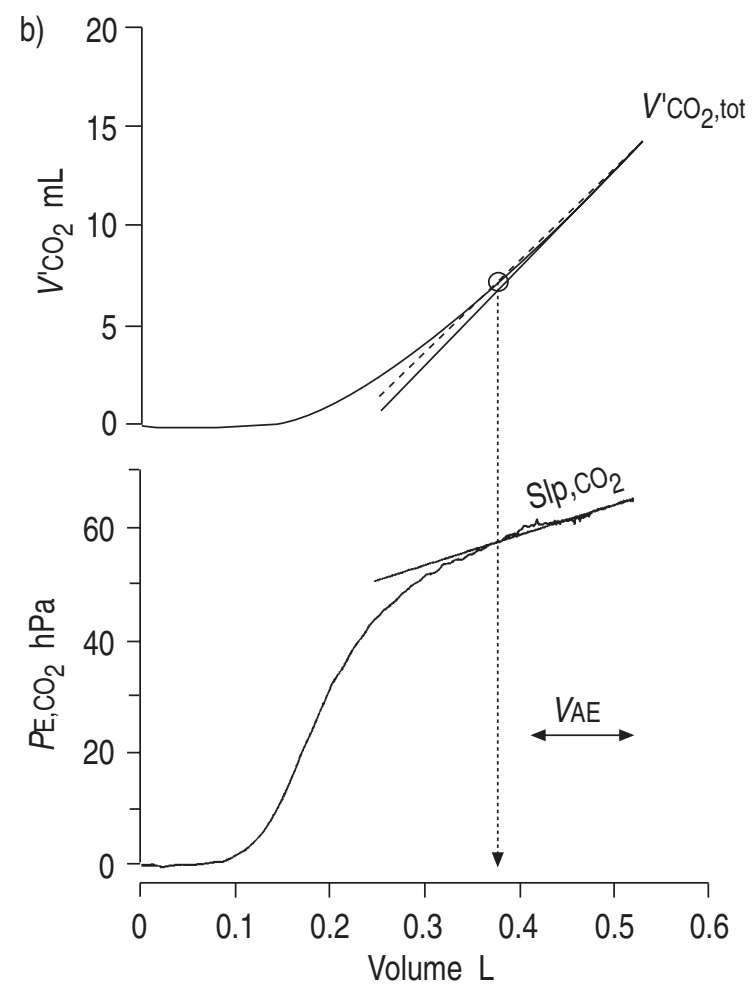

Fig. 1. - Measurement of alveolar ejection to tidal volume $(V \mathrm{AE} / V \mathrm{~T})$ in a) a normal subject and b) a subject with acute respiratory distress syndrome (ARDS). Upper curves represent $\mathrm{CO}_{2}$ elimination versus volume $\left(V^{\prime} \mathrm{CO}_{2}(V)\right)$ curve as a function of expired volume: a first order polynomial is fitted to the last 50 points of the curve, and the equation of this line is represented. A second line is calculated by multiplying the slope by 0.95 (dead space allowance (DSA) of 5\%). $V$ AE is defined as the cross-point between this second line and the experimental $V{ }^{\prime} \mathrm{CO}_{2}(\mathrm{~V})$ curve. Lower curves represent the expiratory partial pressure of $\mathrm{CO}_{2}$ versus volume $\left(P \mathrm{E}, \mathrm{CO}_{2}(\mathrm{~V})\right)$ curve. Traditional identification of Phase III slope $\left(\mathrm{Slp}, \mathrm{CO}_{2}\right)$ by eye is represented. $V^{\prime} \mathrm{CO}_{2}$,tot: total amount of $\mathrm{CO}_{2}$ eliminated in a single expiration. $F \mathrm{~A}^{\mathrm{CO}_{2}}$ : alveolar concentration of $\mathrm{CO}_{2}$. 


\section{Statistical analysis}

Interindividual variability (VI) was obtained by averaging the coefficients of variation of all three cycles at mid-tidal volume:

$$
\mathrm{VI}=\left(\sigma_{1} / \mathrm{m}_{1}+\sigma_{2} / \mathrm{m}_{2}+\sigma_{3} / \mathrm{m}_{3}\right) / 3
$$

expressed in percentage (VI\%). Subindices 1, 2 and 3 refer to the 1 st, 2 nd and 3 rd cycle, respectively. Intraindividual variability (Vi) was obtained as the average of individual coefficients of variation at mid-tidal volume:

$$
\mathrm{Vi}=\Sigma \mathrm{CV}_{\mathrm{j}} / \mathrm{n}
$$

expressed in percentage $(\mathrm{Vi} \%)$. Where $\mathrm{CV}_{\mathrm{j}}$ is the coefficient of variation of three cycles in subject $j$, and $n$ the number of subjects. NSR was estimated from the quotient $\mathrm{Vi} / \mathrm{VI}[1]$.

Average values from the three cycles studied in each patient at each $V \mathrm{~T}$ were used for statistical analysis. Differences between normal subjects and ARDS patients were tested by multifactorial analysis of covariance (ANCOVA) with $V \mathrm{~T}$ as covariate. One-way analysis of

Table 2. - Mean value, variability and noise-to-signal ratio (NSR) for capnographic indices in the Normal group and ARDS group at mid-tidal volume

\begin{tabular}{lcclll}
\hline & $\begin{array}{c}\text { Sl50N } \\
\mathrm{L}^{-1}\end{array}$ & $\begin{array}{c}\text { Sl75N } \\
\mathrm{L}^{-1}\end{array}$ & $V \mathrm{AE} / V \mathrm{~T}$ & $V \mathrm{D}$, Bohr/VT & Effc \\
\hline Normal group & & & & & \\
Mean & 0.196 & 0.161 & 0.637 & 0.329 & 0.570 \\
Vi \% & 10.96 & 34.48 & 2.12 & 3.47 & 4.99 \\
VI \% & 24.56 & 50.67 & 5.42 & 7.12 & 11.33 \\
NSR & 0.45 & 0.57 & 0.39 & 0.49 & 0.44 \\
ARDS group & & & & & \\
Mean & 0.937 & 0.640 & 0.360 & 0.438 & 0.379 \\
Vi \% & 7.43 & 14.79 & 7.23 & 1.45 & 2.15 \\
VI \% & 13.61 & 27.54 & 13.52 & 3.15 & 7.29 \\
NSR & 0.55 & 0.54 & 0.53 & 0.46 & 0.29 \\
\hline
\end{tabular}

Mean values correspond to units indicated. The rest of the values are either percentages or dimensionless. Vi: intraindividual variability; VI: interindividual variability; S175N, and Sl50N: phase II slopes at 75 and $50 \%$ tidal volume $(V T)$, respectively; $V \mathrm{AE} / V \mathrm{~T}$ : alveolar ejection ratio; $V \mathrm{D}, \mathrm{Bohr} / V \mathrm{~T}$ : Bohr's dead space ratio; Effc: Fletcher's efficiency index. variance (ANOVA) was used to determine the statistical significance of intragroup differences. In the case that normality tests and/or the equal variance tests failed, the Kruskal-Wallis nonparametric rank test was used. Values of $\mathrm{F}$ ( or $\chi^{2}$ ), and two-tailed $\mathrm{p}$ are usually given. In all instances, $\alpha=5 \%$. A p-value of less than 0.05 was considered significant.

Partial linear correlations, controlled for ventilator settings, were used to determine the relationship between capnographic indices and mechanical parameters.

\section{Results}

\section{Variability analysis}

Table 2 shows the average and standard deviation of capnographic indices, as well as the results of the analysis of variability, in both groups at mid $V \mathrm{~T}$. The lowest variability and NSR were found in $V \mathrm{AE} / V \mathrm{~T}$ in normal subjects. In ARDS patients, both Effc and $V \mathrm{D}, \mathrm{Bohr} / V \mathrm{~T}$ presented the lowest variability.

\section{ARDS patients versus normal subjects}

Average and standard deviation values for different capnographic indices in the Normal and ARDS groups at the three levels of $V \mathrm{~T}$, are presented in table 3. As $V \mathrm{~T}$ was significantly different between normal subjects and ARDS patients at mid and high levels, betweengroup differences were tested by means of a factorial ANCOVA, with $V \mathrm{~T}$ as covariant. Differences were significant for all capnographic parameters studied, at a very low error level. The effect of $V \mathrm{~T}$ on mechanical parameters is presented in table 4. Factorial ANCOVA with $V \mathrm{~T}$ as covariant showed significant between-group differences for all variables.

\section{Tidal volume effect}

With the exception of $V \mathrm{AE} / V \mathrm{~T}$, all capnographic parameters changed significantly with volume in both groups.

\begin{tabular}{|c|c|c|c|c|c|c|c|c|}
\hline & & \multirow{2}{*}{$\begin{array}{c}\text { Low } \\
V \mathrm{~T}\end{array}$} & \multirow{2}{*}{$\begin{array}{c}\text { Mid } \\
V_{\mathrm{T}}\end{array}$} & \multirow{2}{*}{$\begin{array}{c}\text { High } \\
V_{\mathrm{T}}\end{array}$} & \multicolumn{2}{|c|}{ ANOVA } & \multicolumn{2}{|c|}{ ANCOVA } \\
\hline & & & & & $\mathrm{F}$ & p-value & $\mathrm{F}$ & $\mathrm{p}$-value \\
\hline$V \mathrm{~T} \quad \mathrm{~L}$ & $\begin{array}{l}\text { Normal } \\
\text { ARDS }\end{array}$ & $\begin{array}{l}0.38 \pm 0.02 \\
0.33 \pm 0.05\end{array}$ & $\begin{array}{l}0.56 \pm 0.03 \\
0.49 \pm 0.06\end{array}$ & $\begin{array}{l}0.81 \pm 0.02 \\
0.69 \pm 0.04\end{array}$ & & & & \\
\hline Sl75N L L-1 & $\begin{array}{l}\text { Normal } \\
\text { ARDS }\end{array}$ & $\begin{array}{l}0.29 \pm 0.11 \\
1.29 \pm 0.37\end{array}$ & $\begin{array}{l}0.16 \pm 0.07 \\
0.64 \pm 0.18\end{array}$ & $\begin{array}{l}0.14 \pm 0.04 \\
0.56 \pm 0.24\end{array}$ & $\begin{array}{l}5.84 \\
9.88\end{array}$ & $\begin{array}{l}0.013 \\
0.004\end{array}$ & 44.9 & $<0.001$ \\
\hline Sl50N $L^{-1}$ & $\begin{array}{l}\text { Normal } \\
\text { ARDS }\end{array}$ & $\begin{array}{l}0.93 \pm 0.27 \\
3.01 \pm 1.26\end{array}$ & $\begin{array}{l}0.20 \pm 0.05 \\
0.94 \pm 0.13\end{array}$ & $\begin{array}{l}0.12 \pm 0.02 \\
0.58 \pm 0.10\end{array}$ & $\begin{array}{l}48.4 \\
13.8\end{array}$ & $\begin{array}{r}<0.001 \\
0.010\end{array}$ & 10.2 & $<0.003$ \\
\hline$V \mathrm{AE} / V \mathrm{~T}$ & $\begin{array}{l}\text { Normal } \\
\text { ARDS }\end{array}$ & $\begin{array}{l}0.48 \pm 0.04 \\
0.29 \pm 0.03\end{array}$ & $\begin{array}{l}0.64 \pm 0.03 \\
0.36 \pm 0.05\end{array}$ & $\begin{array}{l}0.75 \pm 0.04 \\
0.35 \pm 0.11\end{array}$ & $\begin{array}{c}73.1 \\
1.43\end{array}$ & $\begin{array}{r}<0.001 \\
0.282\end{array}$ & 92.1 & $<0.001$ \\
\hline$V \mathrm{D}, \mathrm{Bohr} / V \mathrm{~T}$ & $\begin{array}{l}\text { Normal } \\
\text { ARDS }\end{array}$ & $\begin{array}{l}0.44 \pm 0.03 \\
0.54 \pm 0.03\end{array}$ & $\begin{array}{l}0.33 \pm 0.03 \\
0.44 \pm 0.01\end{array}$ & $\begin{array}{l}0.24 \pm 0.04 \\
0.34 \pm 0.09\end{array}$ & $\begin{array}{l}60.9 \\
16.5\end{array}$ & $\begin{array}{l}<0.001 \\
<0.001\end{array}$ & 43.2 & $<0.001$ \\
\hline Effc & $\begin{array}{l}\text { Normal } \\
\text { ARDS }\end{array}$ & $\begin{array}{l}0.44 \pm 0.05 \\
0.26 \pm 0.08\end{array}$ & $\begin{array}{l}0.57 \pm 0.02 \\
0.38 \pm 0.03\end{array}$ & $\begin{array}{l}0.66 \pm 0.08 \\
0.50 \pm 0.19\end{array}$ & $\begin{array}{c}23.7 \\
5.66\end{array}$ & $\begin{array}{r}<0.001 \\
0.020\end{array}$ & 82.8 & $<0.001$ \\
\hline
\end{tabular}

Table 3. - Capnographic indices in normal subjects and ARDS patients at three different tidal volumes

Results are presented as mean \pm SD. ANOVA: one-way analysis of variance for intragroup difference of means; ANCOVA: factorial analysis of covariance with $V \mathrm{~T}$ as covariant, for between-groups difference. For further definitions see legend to table 2. 
Table 4. - Mechanical parameters in normal subjects and ARDS patients at three different tidal volumes

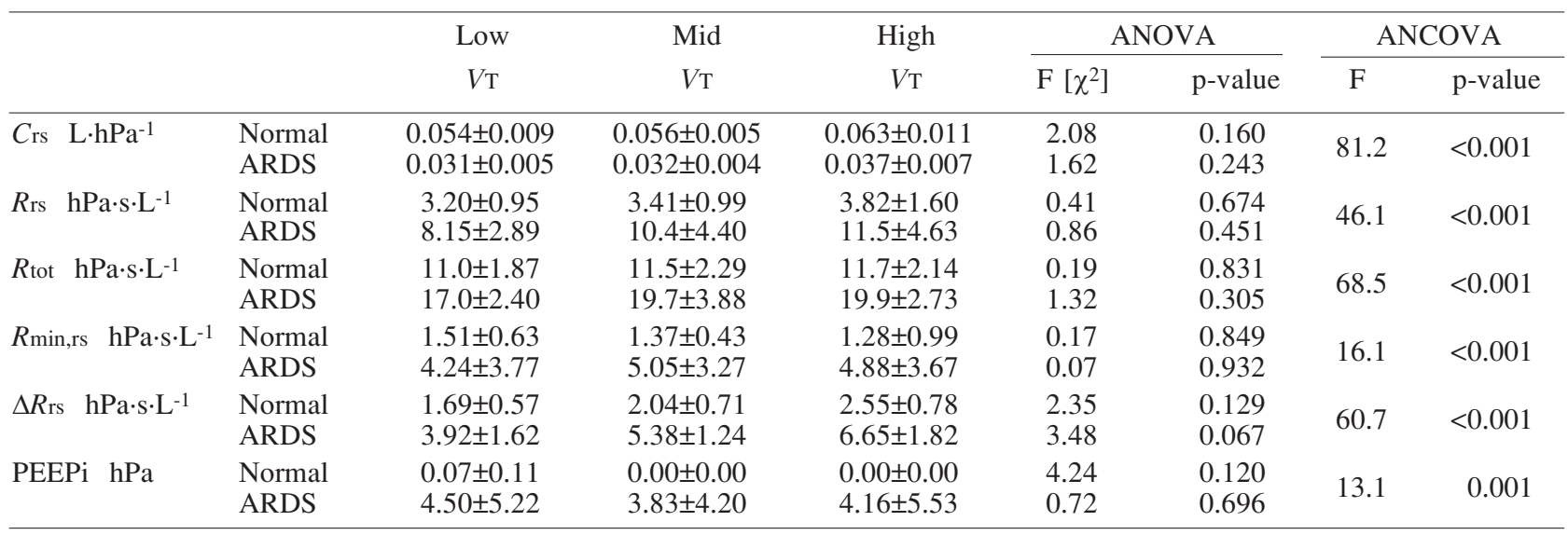

Results are presented as mean \pm SD. $C$ rs: respiratory system compliance; $R$ rs: respiratory system resistance; $R$ tot: $R$ rs plus resistance of the endotracheal tube; $R$ min,rs: Newtonian component of $R$ rs; $\Delta R$ rs: differential resistance; PEEPi: intrinsic positive end-expiratory pressure; ANOVA: one-way analysis of variance for intragroup difference of means; ANCOVA: factorial analysis of covariance with VT as covariant, for between-groups difference. In the case of PEEPi, Kruskal-Wallis test was applied instead of the ANOVA test.

Table 5. - Partial correlation coefficients between capnographic indices and mechanical parameters, adjusted by tidal volume, inspiratory flow, and respiratory frequency

\begin{tabular}{|c|c|c|c|c|c|}
\hline & $\mathrm{Sl} 75 \mathrm{~N}$ & S150N & $V \mathrm{AE} / V \mathrm{~T}$ & $V \mathrm{D}, \mathrm{Bohr} / V \mathrm{~T}$ & Effc \\
\hline$C_{\text {rs }}$ & $-0.17(\mathrm{NS})$ & 0.29 (NS) & $0.47(0.011)$ & $-0.16(\mathrm{NS})$ & $0.27(\mathrm{NS})$ \\
\hline$R \mathrm{rs}$ & 0.19 (NS) & $-0.32(\mathrm{NS})$ & $-0.53(0.003)$ & 0.29 (NS) & -0.36 (NS) \\
\hline$R$ tot & 0.14 (NS) & $-0.37(0.05)$ & $-0.50(0.006)$ & 0.27 (NS) & $-0.39(0.034)$ \\
\hline$R \min , \mathrm{rs}$ & 0.24 (NS) & -0.26 (NS) & $-0.38(0.041)$ & 0.22 (NS) & -0.19 (NS) \\
\hline$\Delta R \mathrm{rs}$ & $0.03(\mathrm{NS})$ & -0.29 (NS) & $-0.56(0.001)$ & 0.31 (NS) & $-0.48(0.009)$ \\
\hline
\end{tabular}

The values presented are Pearson's correlation coefficient (r), and two-tailed statistical significance ( $\mathrm{p}$-value) in parenthesis; Ns: nonsignificant (i.e. $\mathrm{p}>0.05)$. For further definitions see legends to tables 3 and 4.

$V \mathrm{AE} / V \mathrm{~T}$ changed significantly with volume in normal subjects but not in ARDS patients (table 3). No VT dependence was observed in mechanical parameters, except for a tendency for $\Delta R$ rs to increase in ARDS patients (table 4).

\section{Relationship between capnographic indices and respi- ratory system mechanics}

Partial correlations were determined for every capnographic index against every mechanical parameter, as shown in table 5. Correlations were controlled for $V \mathrm{~T}$, inspiratory flow $\left(V^{\prime}\right)$, and respiratory frequency $(f \mathrm{R})$. A significant correlation was found between $R$ tot and S150N. $V \mathrm{AE} / V \mathrm{~T}$ was the best correlated capnographic index. $V \mathrm{AE} / V \mathrm{~T}$ correlated negatively with respiratory system resistances, and positively with $C$ rs. Effc was negatively correlated with $\Delta R$ rs. By contrast, $V \mathrm{D}, \mathrm{Bohr} / V \mathrm{~T}$ failed to correlate with any of the respiratory system mechanical parameters.

\section{Discussion}

The main result of this study is that VAE is a reproducible index, and correlates with lung mechanics in normal subjects and in patients with ARDS. Whereas changes in $V \mathrm{~T}$ did not affect $V \mathrm{AE} / V \mathrm{~T}$ or respiratory mechanics in ARDS, all other volumetric capnographic indices were significantly altered. This suggests that the new computerized physiologically based index, $V \mathrm{AE} / V \mathrm{~T}$, might be useful for monitoring the ventilatory status of critically ill patients despite variations in $V \mathrm{~T}$.

Analysis of variability and NSR showed better reproducibility for $V \mathrm{AE} /$ $V \mathrm{~T}, V \mathrm{D}, \mathrm{Bohr} / V \mathrm{~T}$, and Effc, than for Phase III slopes in normal subjects. The nonlinearity of Phase III between $50 \% V \mathrm{~T}$ and end-expiration explains the difference between S150N and S175N at medium and low volumes, mainly in ARDS patients. Cardiogenic oscillations present at end-expiration and nonlinearity affect the measurements of S150N and S175N to a different extent, the former being more sensitive to the non-linearity and the latter to cardiogenic noise. Differences between normal subjects and ARDS patients could have been influenced by the difference in age between the groups. However, previous studies have shown that the expiratory capnogram does not change, after 18 yrs of age, during adult life in normal subjects [5]. Thus, we can reasonably reject the influence of age on the present results.

In recumbent anaesthetized normal subjects, the increase in $V \mathrm{~T}$ increases ventilatory efficiency. Previous studies in normal subjects [16] have shown that the convection-dependent nonhomogeneity of ventilation increases with relatively small increases in $V \mathrm{~T}$, whereas that due to interaction of convection and diffusion in the lung periphery, decreases. Accordingly, our results suggest that the influence of $V \mathrm{~T}$ on ventilatory maldistribution in normal subjects would be dominated by convection-diffusion interactions. These results agree with those of PAIVA et al. [17], that also showed a reduction in Phase III slope with the increase of $V \mathrm{~T}$ in normal subjects.

Previous studies in patients with ARDS have shown that hypoxemia is due to the presence of shunt and 
regions of very low $V^{\prime} / Q^{\prime}$ ratio $[18,19]$. The multiple inert gas elimination technique has also shown that patients with ARDS have a large percentage of ventilation distributed to unperfused or poorly perfused regions [19]. Using the same technique with oleic acid-injured dogs, Coffey et al. [20] found high $V \mathrm{D} / V \mathrm{~T}$ by increasing shunt, inert gas dead space and mid range $V^{\prime} / Q^{\prime}$ heterogeneity. Our capnographic data are consistent with a high degree of ventilatory maldistribution and a low efficiency for the ventilatory process in these ARDS patients.

Capnographic indices differ in their effect during changes in $V \mathrm{~T}$. All indices except $V \mathrm{AE} / V \mathrm{~T}$ showed significant variations with increasing $V \mathrm{~T}$, while respiratory system mechanics showed no any significant change with volume. The tendency of $\Delta R \mathrm{rs}$ to increase with $V \mathrm{~T}$ in ARDS patients reflects the frequency dependence of tissue resistance [21], as $f \mathrm{R}$ decreased with the increase in $V \mathrm{~T}$. Indeed, it has been shown that $\Delta R$ rs does not change with $V \mathrm{~T}$ in isoflow conditions in patients with ARDS [22]. It might be expected that the increase in $V \mathrm{~T}$ in ARDS patients would recruit some alveolar units, and may, to some extent, improve the degree of alveolar homogeneity [23]. In fact, only if recruited units were strictly normal and homogeneous would they contribute to improvement in ventilatory and mechanical efficiency. However, this contention could reasonably be rejected either because recruited alveoli were diseased, or because increased $V$ T did not effectively recruit new lung areas. In the case of $V \mathrm{D}, \mathrm{Bohr} / V \mathrm{~T}$ or Effc, their change with $V \mathrm{~T}$ can be explained by some degree of amplitude dependence of those indices [14, 24, 25], but does not necessarily imply a true improvement in alveolar ventilatory distribution.

The present results on lung mechanics in ARDS agree with those of other authors, who showed that ARDS adversely affects the mechanical properties of the respiratory system, with reduced compliance as a hallmark, but also by increasing airway, pulmonary and thoracic tissue flow resistance [22, 26]. In a previous study [7], we found a close correlation between expired $\mathrm{CO}_{2}$ slope and total respiratory system resistance in a population of critically ill patients with different degrees of airflow obstruction. In the present investigation, the parameter that best correlated with respiratory system mechanics was $V \mathrm{AE} / V \mathrm{~T}$. Moreover, $R$ tot was correlated with $\mathrm{S} 150 \mathrm{~N}$, confirming that $\mathrm{CO}_{2}$ elimination from alveoli to the atmosphere is modulated by lung, airway and apparatus resistances. This occurred despite the low level of airflow limitation of these patients compared to the patients from the previous study [7].

While the capnographic index best related to the mechanical alterations present in ARDS was $V \mathrm{AE} / V \mathrm{~T}$, the worst correlated was $V \mathrm{D}, \mathrm{Bohr} / V \mathrm{~T}$. The similar behaviour of $V \mathrm{AE} / V \mathrm{~T}$ and $V \mathrm{D}, \mathrm{Bohr} / V \mathrm{~T}$ observed in normal subjects reflects a close relationship between both parameters, as can be observed in figure 2 . This agreement is lost in ARDS patients, according to the different pathophysiological meaning of both indices. Whereas $V \mathrm{AE} / V \mathrm{~T}$ seems to be more sensitive to alterations in distribution (mostly parallel nonhomogeneity), $V \mathrm{D}, \mathrm{Bohr} / V \mathrm{~T}$ reflects global ventilatory efficiency, which includes the fraction of serial dead space, and is, therefore, very sensitive to changes in breathing pattern.

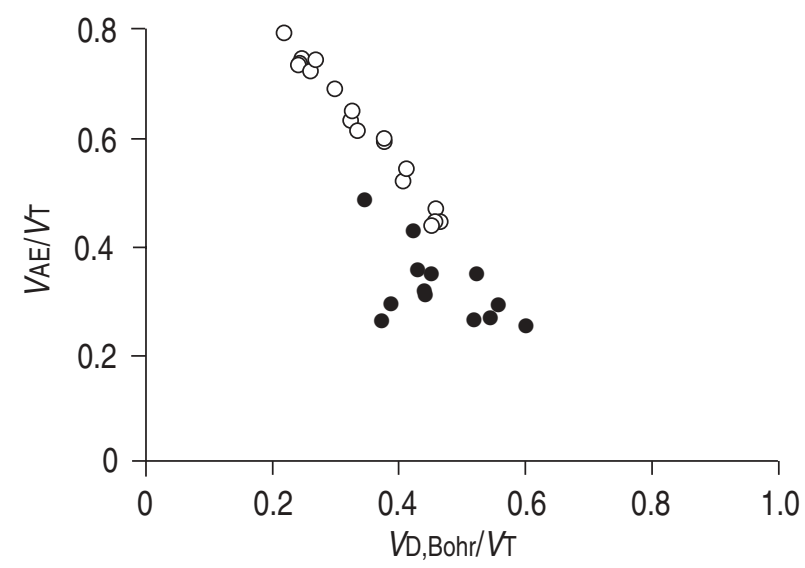

Fig. 2. - Relationship between alveolar ejection fraction to tidal volume ratio $(V \mathrm{AE} / V \mathrm{~T})$ and Bohr's dead space to tidal volume ratio $(V \mathrm{D}, \mathrm{Bohr} / V \mathrm{~T})$ in normal subjects $(\mathrm{O})$ and in patients with acute respiratory distress syndrome $(\bullet)$.

In conclusion, volumetric capnography indices detect important distribution abnormalities in patients with acute respiratory distress syndrome compared to anaesthetized normal subjects during mechanical ventilation. Of the indices studied, the ratio of alveolar ejection volume to tidal volume appears to be the most reproducible and sensitive index to assess ventilatory disturbances. However, further clinical research is needed to assess the value of volumetric capnography indices in patients with different degrees of airflow obstruction and during ventilation with positive end-expiratory pressure.

\section{References}

1. You B, Peslin R, Duvivier C, Dang Vu V, Grilliat JP. Expiratory capnography in asthma: evaluation of various shape indices. Eur Respir J 1994; 7: 318-323.

2. Jordanoglu J, Koulouris N, Dimitroulis J, Rapakoulias $\mathrm{P}$, Alchanatis M, Hadzistavrou C. A new approach to estimate effective alveolar $\mathrm{CO}_{2}$ tension $\left(P \mathrm{~A}, \mathrm{CO}_{2}\right.$,eff $)$ using the expired $\mathrm{CO}_{2}$ volume versus tidal volume curve obtained during spontaneous breathing (Abstract). Eur Respir J 1995; 8 (Suppl. 19): P1235.

3. Kars AH, Goorden G, Stijnen T, Bogaard JM, Verbraak AFM, Hilvering C. Does Phase 2 of the expiratory versus volume curve have diagnostic value in emphysema patients? Eur Respir J 1995; 8: 86-92.

4. Worth H. Expiratory partial pressure curves in the diagnosis of emphysema. Bull Eur Physiopathol Respir 1986; 22: 191-199.

5. Ream RS, Screiner MS, Neff JD, et al. Volumetric capnography in children: influence of growth on the alveolar plateau slope. Anesthesiology 1995; 82: 64-73.

6. You B, Mayeaux D, Rkiek B, Autran N, Dang Vu V, Grilliat JP. Expiratory capnography in asthma. Perspectives in the use and monitoring in children. Rev Mal Respir 1992; 9: 547-552.

7. Blanch L, Fernandez R, Saura P, Baigorri F, Artigas A. Relationship between expired capnogram and respiratory system resistance in critically ill patients during total ventilatory support. Chest 1994; 105: 219-223.

8. Smidt U. Emphysema as possible explanation for the alteration of expiration $\mathrm{PO}_{2}$ and $\mathrm{PCO}_{2}$ curves. Bull Eur Physiopathol Respir 1976; 12: 605-624. 
9. Fletcher R, Jonson B. Dead space and the single-breath test for carbon dioxide during anaesthesia and artificial ventilation. Br J Anaesth 1984; 56: 109-119.

10. Fletcher R, Jonson B, Cumming G, Brew J. The concept of dead space with special reference to the single-breath test for carbon dioxide. Br J Anaesth 1981; 53: 77-88.

11. Murray JF, Matthay MA, Luce JM, Flick MR. An expanded definition of the adult respiratory distress syndrome. Am Rev Respir Dis 1988; 138: 720-723.

12. Sly PD, Bates JHT, Milic-Emili J. Measurement of respiratory mechanics using the Siemens servo Ventilator 900C. Pediatr Pulmonol 1987; 3: 400-405.

13. Bates JHT, Rossi A, Milic-Emili J. Analysis of the behaviour of the respiratory system with constant inspiratory flow. J Appl Physiol 1985; 58: 1840-1848.

14. Rossier PH, Bühlmann A. The respiratory dead space. Physiol Rev 1955; 35: 860-876.

15. Fletcher R. Dead space: invasive and noninvasive. $\mathrm{Br} J$ Anaesth 1985; 57: 245-249.

16. Crawford ABH, Makowska M, Engel LA. Effect of tidal volume on ventilation maldistribution. Respir Physiol 1986; 66: 11-25.

17. Paiva M, Van Muylem A, Ravez P, Yernault JC. Inspired volume dependence of the slope of alveolar plateau. Respir Physiol 1984; 56: 309-325.

18. Dantzer DR, Brook CJ, Dehart P, Lynch JP, Weg JG. Ventilation-perfusion distributions in the adult respiratory distress syndrome. Am Rev Respir Dis 1979; 120: 1039-1052.

19. Ralph DD, Robertson HT, Weaver LJ, Hlastala MP, Carrico CJ, Hudson LD. Distribution of ventilation and perfusion during positive end-expiratory pressure in the adult respiratory distress syndrome. Am Rev Respir Dis 1985; 131: 54-60.

20. Coffey RL, Albert RK, Robertson HT. Mechanisms of physiological dead space response to PEEP after acute oleic acid lung injury. $J$ Appl Physiol: Respirat Environ Exercise Physiol 1983; 55: 1550-1557.

21. D'Angelo E, Calderini E, Torri G, Robatto FM, Bono D, Milic-Emili J. Respiratory mechanics in anesthetized paralyzed humans: effects of flow, volume and time. $J$ Appl Physiol 1989; 67: 2556-2564.

22. Auler JOC, Saldiva PHN, Martins MA, et al. Flow and volume dependence of respiratory system mechanics during constant flow ventilation in normal subjects and in adult respiratory distress syndrome. Crit Care Med 1990; 18: 1080-1086.

23. Blanch L, Fernandez R, Vallés J, Solé J, Roussos C, Artigas A. Effect of two tidal volumes on oxygenation and respiratory system mechanics during the early stage of adult respiratory distress syndrome. J Crit Care 1994; 9: 151-158.

24. Baker RW, Burki NK. Alterations in ventilatory pattern and ratio of dead space to tidal volume. Chest 1987; 92: 1013-1017.

25. Lifshay A, Fast CW, Glazier JB. Effect of changes in respiratory pattern on physiological dead space. J Appl Physiol 1971; 31: 478-483.

26. Pelosi P, Cereda M, Foti G, Giacomini M, Pesenti A. Alterations of lung and chest wall mechanics in patients with acute lung injury: effects of positive end-expiratory pressure. Am J Respir Crit Care Med 1995; 152: 531-537. 